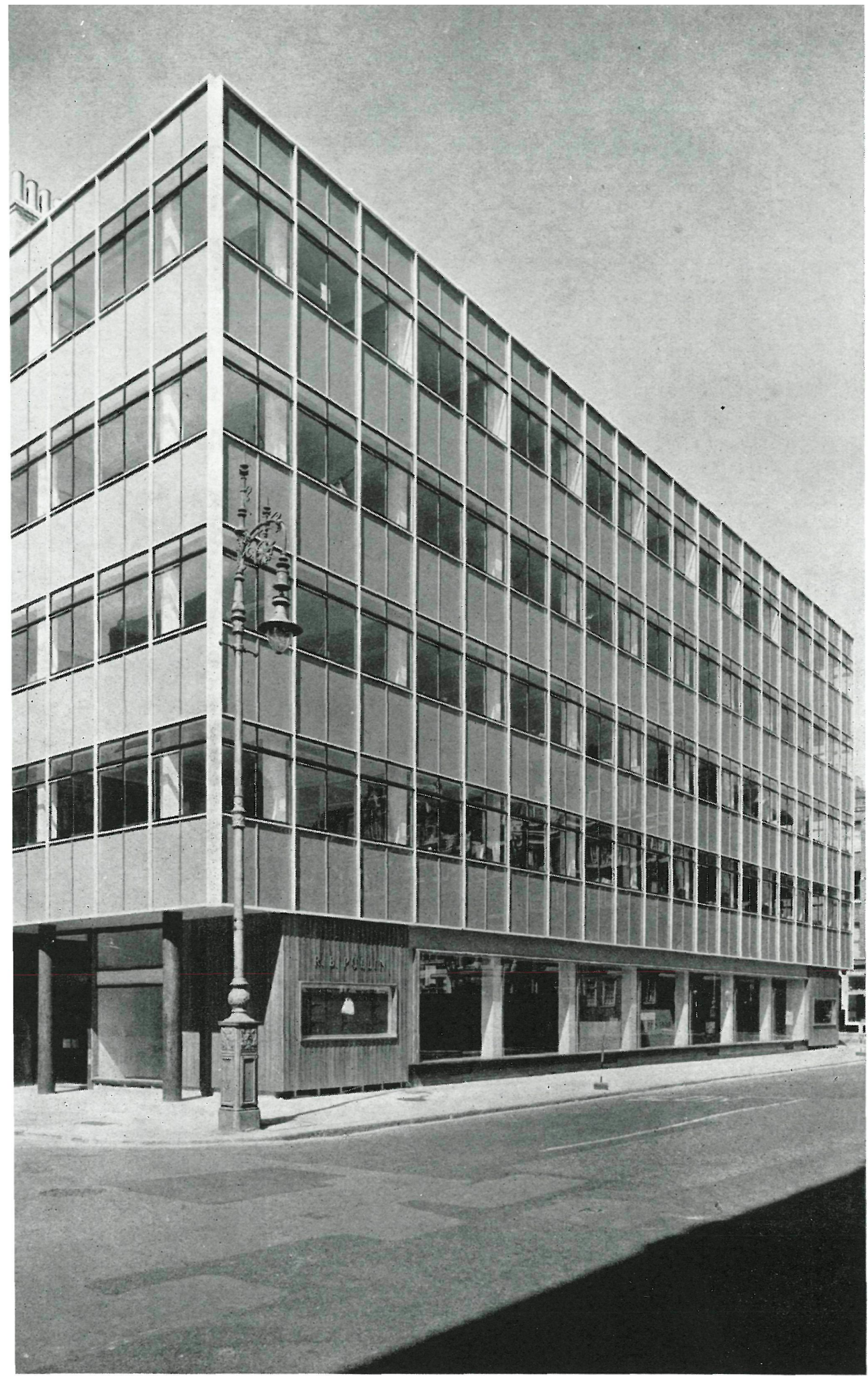

\title{
electric house
}

GOLLINS, MELVIN, WARD y asociados

$125 \cdot 32$

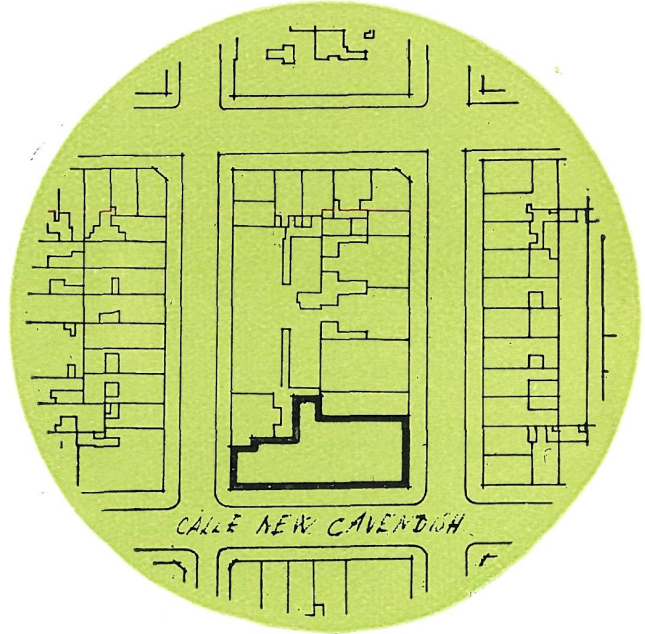

Este edificio de oficinas, de traza sencilla y luminosa y de gran ligereza y esbeltez aparentes, ha sido levantado en el corazón de Londres. Por este motivo, presentaba un serio problema de adaptación a los viejos edificios de la ciudad, todos ellos de configuración muy semejantes y de tratamiento completamente distintos a los que ahora se acostumbran a emplear.

Está situado en la acera norte de la calle New Cavendish, entre las calles Bolsover y Great Titchfield. 


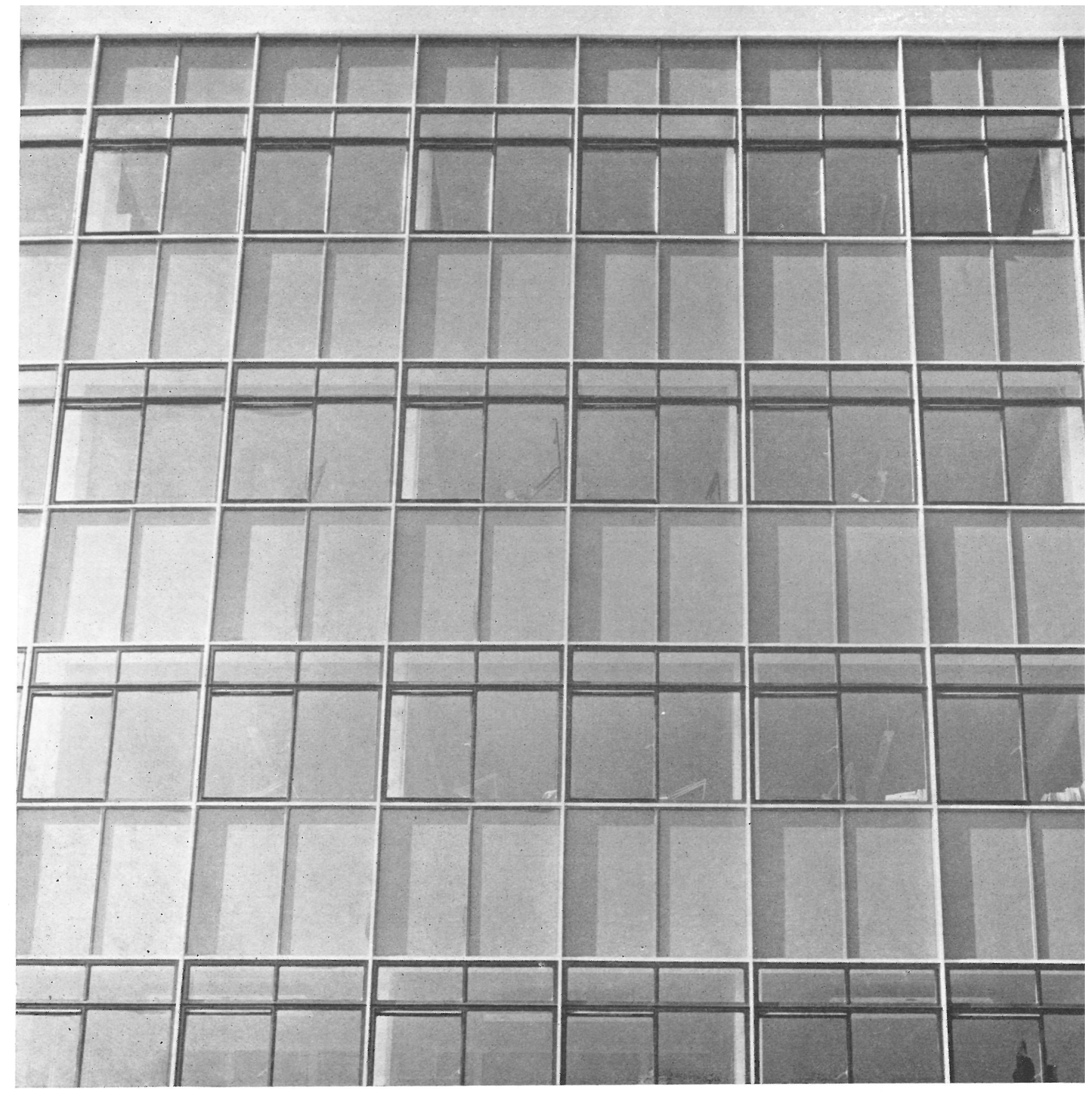

Las premisas rectoras obligadas en este tipo de edificios son: espacio máximo aprovechable para oficinas; gran diafanidad de fachadas para conseguir la máxima comodidad en el trabajo; planta baja comercial.

Los autores del proyecto han realizado su obra con absoluta libertad, sin dejarse impresionar por los edificios de otra época que lo circundan, y expresando, con noble sinceridad descriptiva, lo que siente y dice la arquitectura en nuestros días, pero ateniéndose a las Ordenanzas de altura y alineación municipal y a un sensitivo concepto de armonizar dos cstilos tan dispares.

La estructura es de hormigón armado remetida de la fachada, encerrada en una caja de acero, aluminio y cristal, modulada en retícula severa y de línea elemental, constituyendo el clásico muro-cortina, de uso tan frecuente, con bandas alternadas de vidrio azul-gris y zonas de ventanas con la carpintería en negro y nervios verticales de aluminio anodizado. 


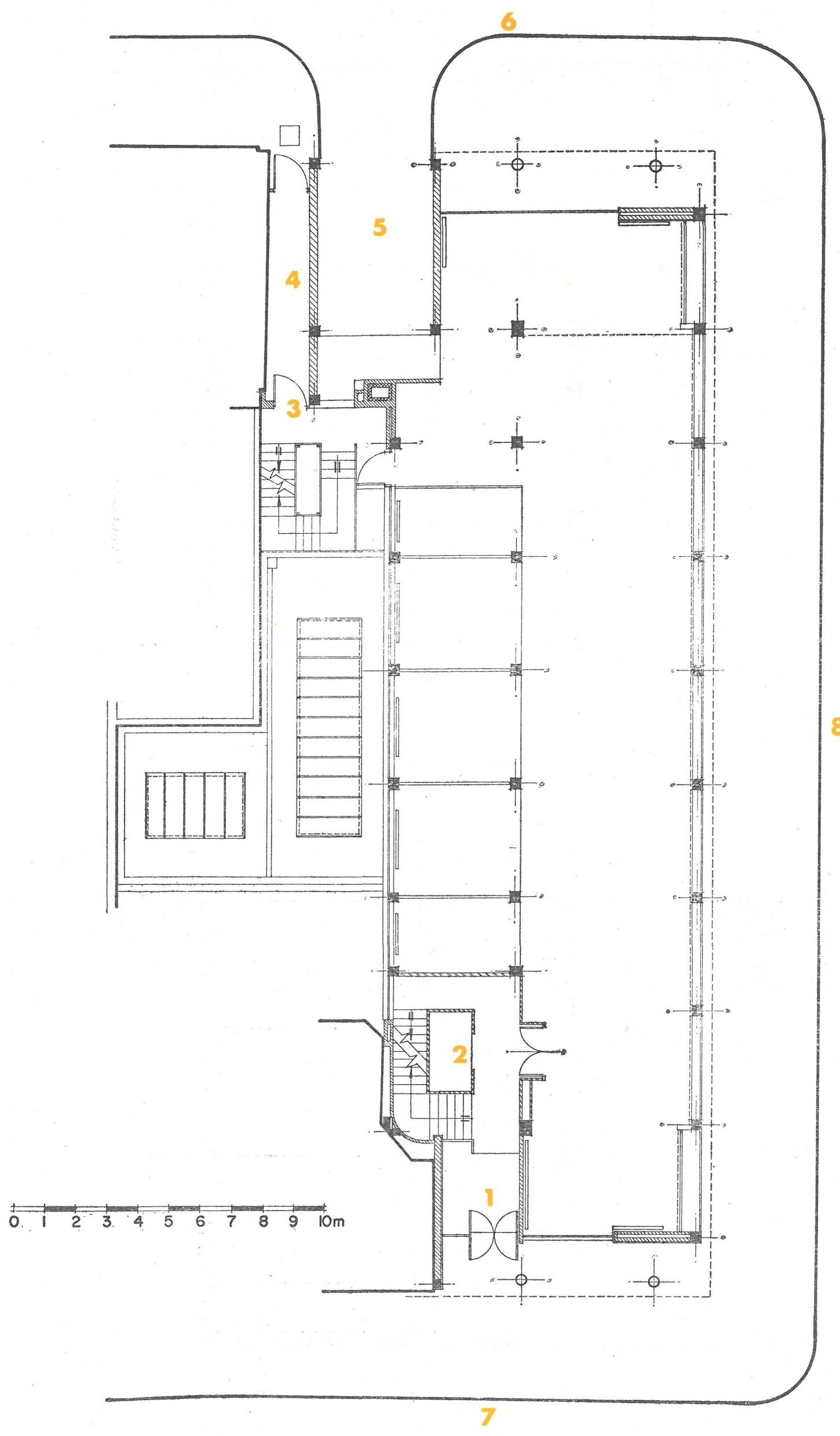

Hall. 1

Hueco del ascensor. 2 Plataforma de descarga. 3 Pasaje-salida contra incendios. 4 Muelle de descarga. 5 Calle Great Titchfield. 6 Calle Bolsover. 7 Calle New Cavendish. 8 
$p l a n+a$

\section{tipo}

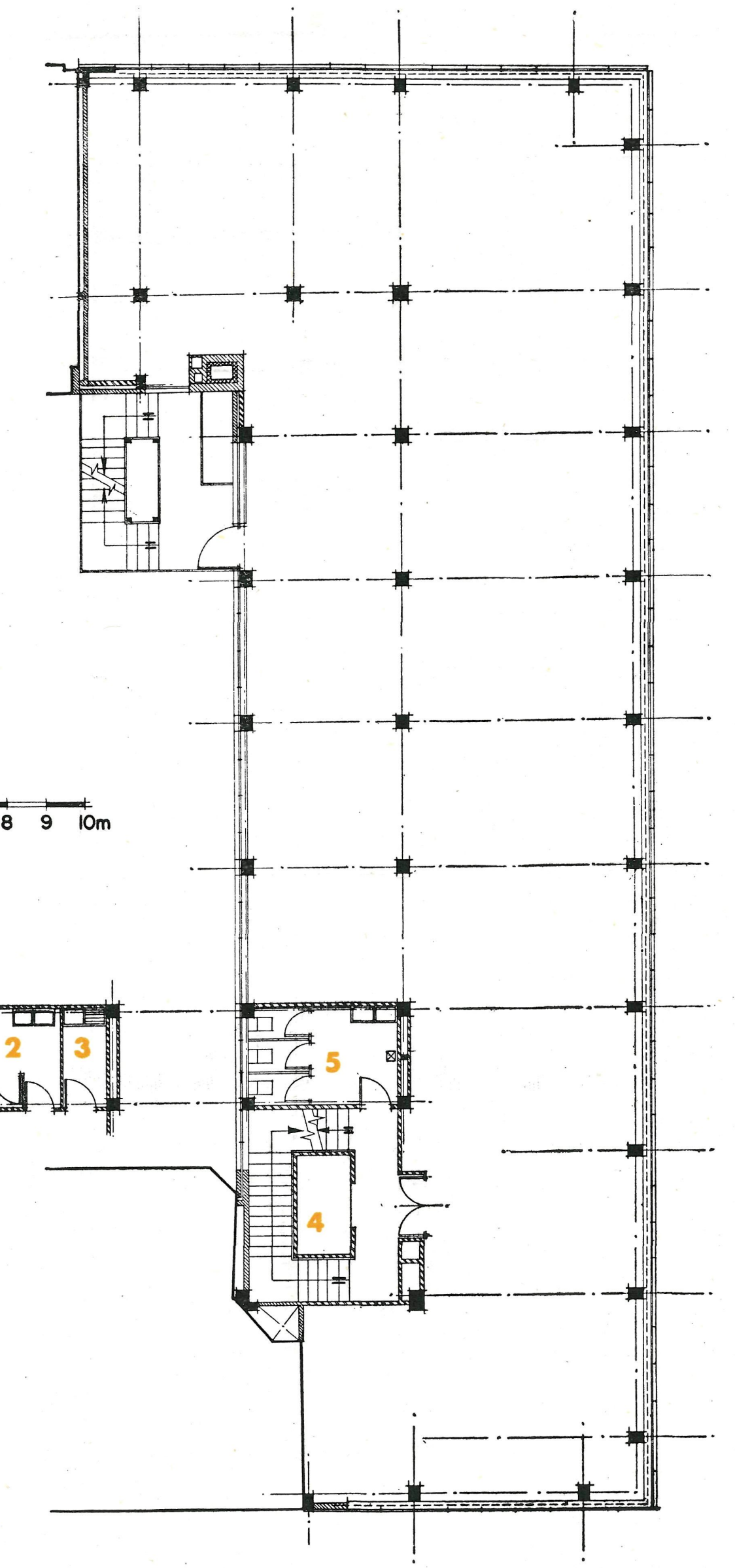

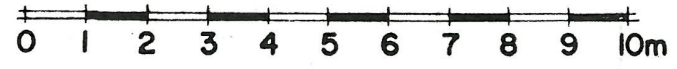

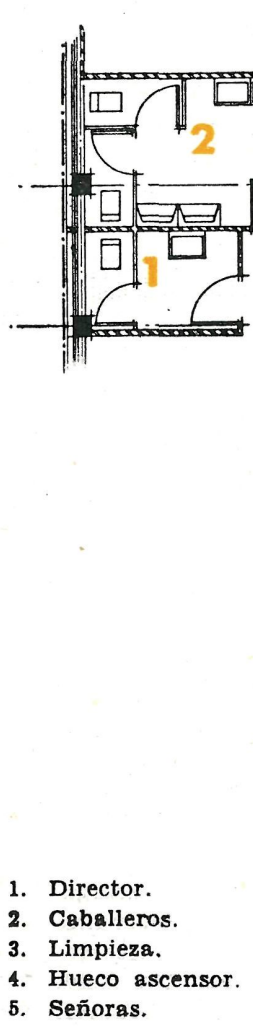

4. Hueco ascensor

5. Señoras. 


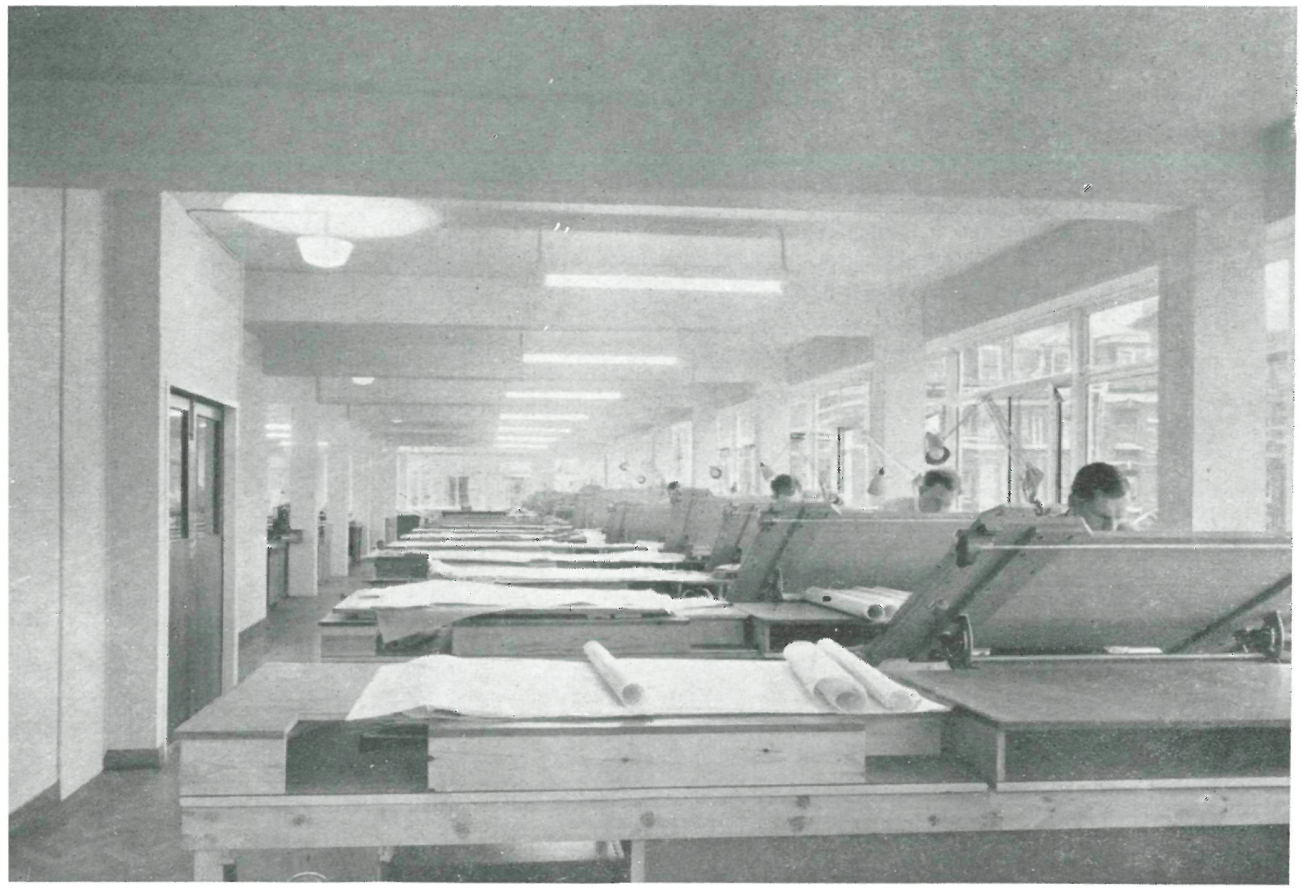

Las plantas altas se distribuyen con gran diafanidad y claro criterio utilitario, planteadas con espacios libres situados a lo largo de las fachadas exteriores para su distribución conveniente mediante tabiques móviles. La comunicación vertical se realiza por dos escaleras y un ascensor pegados a las medianerías, La planta baja comprende tiendas y salas de exposición; escaparates hacia la calle. El sótano sólo alberga almacenes y sala de calefacción (por agua caliente a baja presion), salvo en el hall de entrada, que se hace por paneles radiantes.

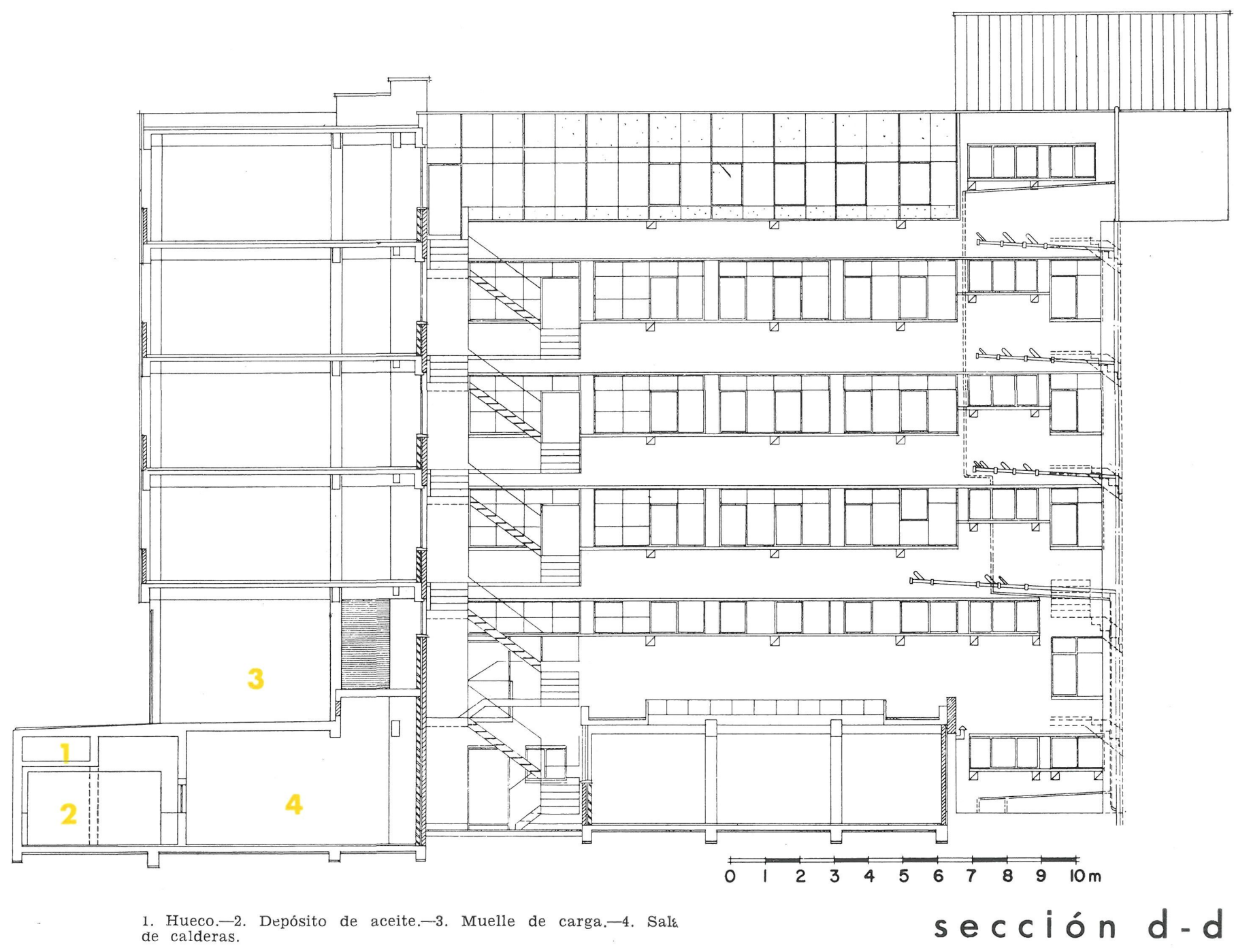




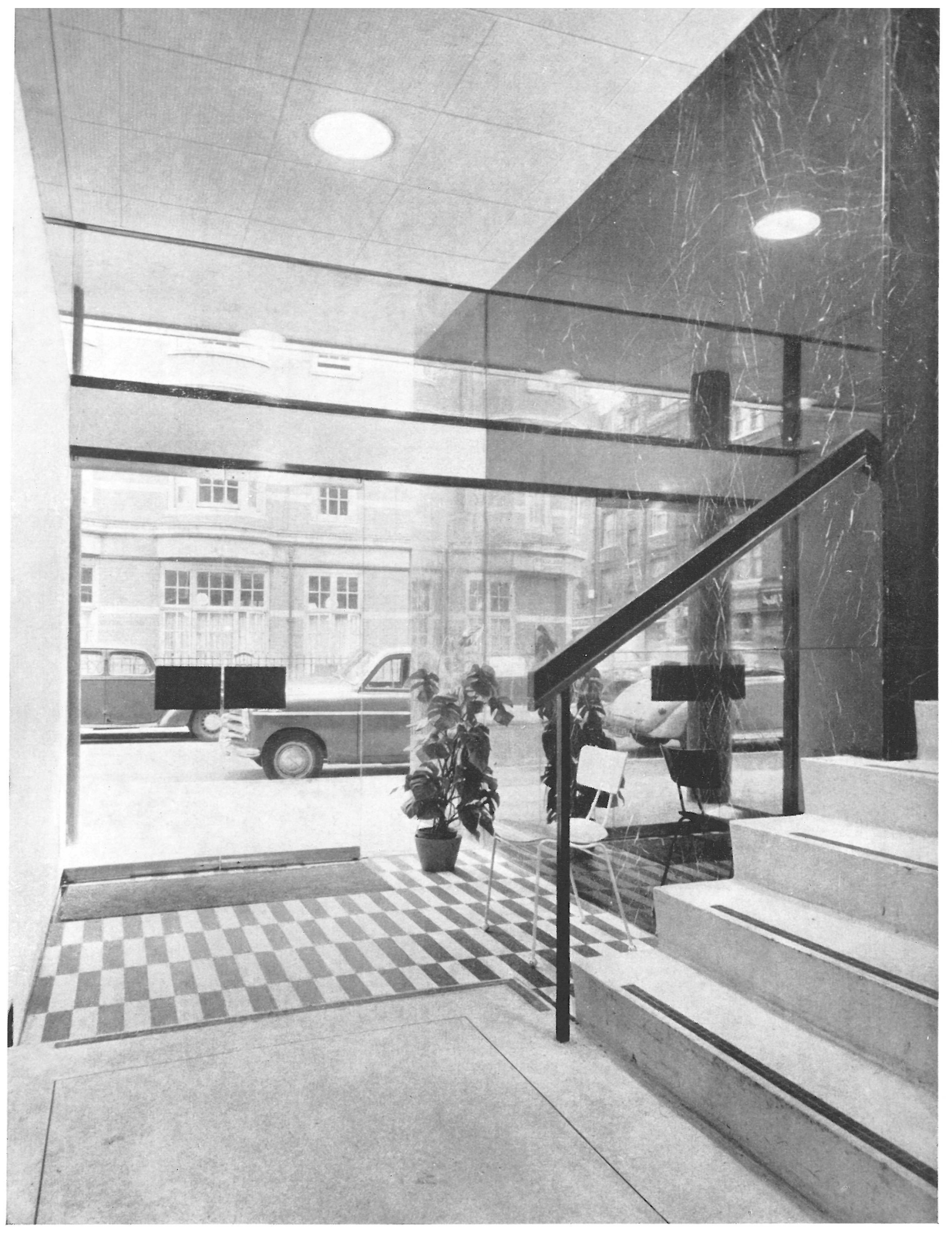

Los materiales empleados en la planta comercial son nobles: madera, terrazo blanco, muro de mármol azul belga y cristalina en escaparates.

La pintura interior, en general, es plástica.

Solución funcional y acertada para el problema presentado con adaptación perfecta de estilo, materiales y sistema constructivo del momento. 